This item was submitted to Loughborough's Research Repository by the author.

Items in Figshare are protected by copyright, with all rights reserved, unless otherwise indicated.

\title{
The Portuguese business cycle: chronology and duration dependence
}

\section{PLEASE CITE THE PUBLISHED VERSION}

http://dx.doi.org/10.1007/s00181-014-0860-4

\section{PUBLISHER}

(C) Springer

\section{VERSION}

AM (Accepted Manuscript)

\section{PUBLISHER STATEMENT}

This work is made available according to the conditions of the Creative Commons Attribution-NonCommercialNoDerivatives 4.0 International (CC BY-NC-ND 4.0) licence. Full details of this licence are available at: https://creativecommons.org/licenses/by-nc-nd/4.0/

\section{LICENCE}

CC BY-NC-ND 4.0

\section{REPOSITORY RECORD}

Castro, Vitor. 2019. "The Portuguese Business Cycle: Chronology and Duration Dependence”. figshare. https://hdl.handle.net/2134/25017. 


\title{
The Portuguese Business Cycle:
}

\section{Chronology and Duration Dependence}

\author{
Vitor Castro* \\ University of Coimbra and NIPE
}

\begin{abstract}
This paper tries to identify a chronology for the Portuguese business cycle and test for the presence of duration dependence in the respective phases of expansion and contraction. A duration dependent Markov-switching vector autoregressive model is employed in that task. This model is estimated over year-on-year growth rates of a set of relevant economic indicators, namely, industrial production, a composite leading indicator and, additionally, civilian employment. The estimated specifications allow us to identify four main periods of contraction during the last three decades and some evidence of positive duration dependence in contractions, but not in expansions, especially when employment is added to the model.
\end{abstract}

Keywords: business cycles; duration dependence; Markov-switching.

JEL Classification: E32, C41, C24.

${ }^{*}$ University of Coimbra, Faculty of Economics, Avenida Dias da Silva, 165, 3004-512 Coimbra, Portugal. University of Minho, Economic Policies Research Unit (NIPE), Campus de Gualtar, 4710-057 Braga, Portugal. E-mail: vcastro@fe.uc.pt 


\section{Introduction}

This study intends to identify a chronology for the Portuguese business cycle and test for the presence of duration dependence in expansions and contractions, i.e. to verify whether those business cycle phases are more likely to end as they become older or not.

The occurrence of the recent global crisis has become key for assessing the timing and duration of business cycle phases and how fiscal and monetary authorities can inłuence economic activity (Agnello and Schuknecht, 2011; Agnello and Sousa, 2011, 2013; Mallick and Sousa, 2013; Sousa, 2010). Indeed, many countries have actively adopted measures to avoid a deep economic contraction in reaction to the crisis that arouse in 2007 in the financial markets. The knowledge of the timing, behaviour and duration of business cycles is important for economic agents to react rationally to this kind of events. However, the study and characterization of the business cycle is still incomplete for some industrial countries. One example is the Portuguese business cycle. As far as we are concerned, no national or international organization or scientific paper have established, so far, a clear chronology for the Portuguese business cycle or tested for the presence of duration dependence in the respective phases of expansion and contraction.

The aim of this paper is to fill that gap in the literature. Therefore, we implement a procedure to identify the respective chronology and that simultaneously allows to test for the presence of duration dependence. The procedure implemented here was first developed and employed by Pelagatti $(2001,2002)$ to study the US business cycle. It presents significant improvements relatively to the basic Markov-switching approach introduced by Hamilton (1989) and has proved to work well in the identification of the respective chronology and in testing for duration dependence. We apply this duration dependence Markov-switching model to the Portuguese case estimating it over a set of monthly economic indicators, like the industrial production index, a composite leading indicator and, additionally, civilian employment for the period 1978-2010.

The fitted models generate an interesting chronology for the Portuguese business cycle, permitting us to identify four main periods of contraction during the last three decades. Moreover, the results also point out to the presence of positive duration dependence in 
contractions, while the likelihood of expansions ending is not affected by their duration.

The rest of the paper is organized as follows. Section 2 presents a brief review of the literature. The econometric model and the estimation procedures are discribed in Section 3. The empirical results are reported and discussed in Section 4. Finally, Section 5 concludes emphasizing the main findings of this paper.

\section{Review of the literature}

The identification of peaks and troughs in the business cycle and the respective phases of expansion and contraction dates back to the seminal works of Fisher (1925) and Burns and Mitchell (1946). These authors were the first to analyse the mechanisms by which output alternates between states of expansion and contraction and to study the effect of their duration on the transition probabilities between those states.

Based on their studies, the National Bureau of Economic Research (NBER) has been publishing a business cycle chronology for the United States (US) since 1929. In 1978, the NBER introduced new procedures. In particular, the business cycle turning points for the US economy started to be officially determined by a Committee of experts. This Committee takes into account a large range of macroeconomic indicators and uses a consistent methodology to date the business cycle. ${ }^{1}$ More recently, the Economic Cycle Research Institute (ECRI) and the Centre for Economic Policy Research (CEPR) started to produce similar chronologies for other countries and for the Euro Area, respectively, based on NBER's methodology and also relying on a Committee of experts. ${ }^{2}$

The main weakness of this methodology of dating the business cycle is the significant lag of time that usually elapses from the occurrence of a turning point until its announcement by the respective Committees. Nevertheless, the careful analysis of relevant economic indicators by a group of experts guarantees a very reliable identification of the respective peaks and troughs in the economy. Unfortunately, no national or international organization have produced, so

\footnotetext{
${ }^{1}$ For further details contact the NBER at http://www.nber.org/cycles/cyclesmain.html.

${ }^{2}$ For further details contact the ECRI at http://www.businesscycle.com/resources/cycles/ and the CEPR at http://www.cepr.org/data/Dating/.
} 
far, a similar chronology for Portugal. Therefore, we cannot rely on the traditional duration analysis to test for the presence of duration dependence in the phases of the Portuguese business cycle. ${ }^{3}$

An alternative procedure that has been widely used to date the business cycle is the Markov-switching (MS) approach. This procedure, introduced by Hamilton (1989), models the business cycle as the outcome of a Markov process that switches between two discrete states: expansions and contractions. This method regards the business cycle as an unobserved stochastic process, so that the reference turning point dates identified by the NBER, CEPR or ECRI are not necessary a priori. Moreover, it has the advantage of being employed to identify the business cycle chronology in countries for which there is no organization in charge of doing that. Besides dating the business cycle, it also allows for a simultaneous estimation of some parameters of interest, like the mean growth rates in each state. Some later developments and improvements make it possible to include duration dependence parameters in the model (Durland and McCurdy, 1994; and Kim and Nelson, 1998) and to estimate it over a vector of relevant time series - the so called MSVAR model - and not simply over a single time series (Krolzig, 1997; Krolzig, 2001; Artis et al., 2004; Krolzig and Toro, 2005; and Schirwitz, 2007). ${ }^{4}$

Pelagatti (2001, 2002) combines these two improvements and employs Bayesian inference in the estimation of the model, which gives rise to the so called duration dependent Markovswitching vector autoregressive model (henceforth, DDMSVAR). This approach has some advantages over the standard (asymptotic) maximum likelihood theory for inference used by Durland and McCurdy (1994): first, it does not rely on asymptotic approximations since the posterior can be computed exactly; second, inference on the latent variables is not conditional on the estimated parameters, but incorporates also the parameters' variability. Furthermore,

\footnotetext{
${ }^{3}$ On duration analysis using duration models see, among others, Sichel (1991), Diebold et al. (1990, 1993), Zuehlke (2003), Davig (2007) and Castro (2010).

${ }^{4}$ Another basic procedure to date the business cycle is the algorithm proposed by Bry and Boschan (1971) to pin-point the relevant turning points in a dataseries. However, it presents an important drawback: it is only applicable to a single monthly series. Harding and Pagan (2002) solves part of the problem extending the algorithm to quarterly data, but its application remains restricted to a single series. An even simpler procedure is the GDP growth rule, which defines a recession as a period of negative growth of real GDP that lasts two or more consecutive quarters. But, once again, it only relies on a single series which means that not all relevant information is considered. Hence, these two procedures may not be able to capture the true underlying business cycle.
} 
Pelagatti (2001, 2002) develops and employs a generalized multivariate DDMSVAR model in which the inference on the state variable is carried out using a multi-move Gibbs sampler, while Kim and Nelson (1998) rely on a univariate model and on a single-move Gibbs sampler for inference, which results in a slower convergence to the invariant distribution.

Pelagatti $(2001,2002)$ applies this model to the US economy and shows that it reproduces quite accurately the business cycle turning points identified by the NBER. Moreover, the model indicates the presence of positive duration dependence in US contractions but not in expansions. Some evidence of duration dependence is also found by Chen and Shen (2006) and Ozun and Turk (2009), respectively, in the Taiwanese and Turkish business cycle phases, using this model.

To our knowledge the paper by Correia et al. (1992) was the first to describe the most important features of the Portuguese business cycle during the period 1958-1989. In that influential paper two standard dynamic general equilibrium models are used to characterize the business cycle. Following these first steps, Neves (1994), Dias (1997) and Neves and Belo (2002) apply the Hodrick-Prescott filter over GDP series also to describe the Portuguese business cycle, but, once again, without identifying a chronology for its peaks and troughs. Dias (2003) employs a nonlinear smooth transition autoregressive model to check for an asymmetric cyclical behaviour in Portuguese contractions and expansions and identifies two periods of low growth: 1983:2-1985:4 and 1992:3-1994:1. More recent studies look at the business cycle from very different perspectives: Cavalcanti (2007) analyses the effects of economic efficiency on the Portuguese business cycle using a stochastic growth model, while Afonso et al. (2011) employ an MS model to study the changes in fiscal policy regimes and its behaviour over the economic cycle in Portugal. Nevertheless, none of the abovementioned studies analyzes the presence of duration dependence in the phases of expansion and contraction in the Portuguese economy. That is an important issue that we intend to address in this paper. Moreover, only Dias (2003) presents a brief attempt to date the Portuguese business cycle. As he only uses a GDP series to characterize it, we may not regard that as a "classical business cycle" chronology, but as a "growth cycle" chronology. Thus, in this paper, with the set of variables/information used, we intend to update and generate 
a chronology that resembles the classical peaks and troughs that are usually identified by international intitutions for other countries.

\section{Econometric Model}

The econometric model, which is drawn upon the work of Pelagatti (2001, 2002, 2003), is presented in this section. The duration dependent Markov-switching vector autoregressive (DDMSVAR) model is defined by:

$$
\mathbf{y}_{t}=\boldsymbol{\mu}_{0}+\boldsymbol{\mu}_{1} S_{t}+\mathbf{A}_{1}\left(\mathbf{y}_{t-1}-\boldsymbol{\mu}_{0}-\boldsymbol{\mu}_{1} S_{t-1}\right)+\ldots+\mathbf{A}_{p}\left(\mathbf{y}_{t-p}-\boldsymbol{\mu}_{0}-\boldsymbol{\mu}_{1} S_{t-p}\right)+\varepsilon_{t}
$$

where $\mathbf{y}_{t}$ is a vector of observable variables, $S_{t}$ is a binary unobservable random variable following a Markov chain with varying transition probabilities and that takes value 1 when the economy is in expansion and 0 when it is in contraction, $\mathbf{A}_{1}, \ldots, \mathbf{A}_{p}$ are coefficient matrices of a stable VAR process, $\boldsymbol{\mu}_{0}$ and $\boldsymbol{\mu}_{1}$ are the parameter vectors to estimate, and $\boldsymbol{\varepsilon}_{t}$ is a gaussian white noise vector with covariance matrix $\Sigma$.

In order to achieve duration dependence for $S_{t}$, a Markov chain is now built for the pair $\left(S_{t} ; D_{t}\right)$, where $D_{t}$ is the duration variable. This variable $\left(D_{t}\right)$ counts the number of periods in which $S_{t}$ has been in the current state. The probability of $S_{t}$ being in a particular state is assumed to be dependent on the previous state $S_{t-1}$ and on the duration dependent variable $D_{t-1}$. Hence, given $S_{t-1}, S_{t}$ and $D_{t-1}$, we can determine $D_{t}$ as follows:

$$
D_{t}=\left\{\begin{array}{ccc}
D_{t-1}+1 & \text { if } & S_{t}=S_{t-1} \\
1 & \text { if } & S_{t} \neq S_{t-1}
\end{array}\right.
$$

Therefore, according to Pelagatti (2003, pp. 3-5), we can assume the following nonhomogeneous Markov chain with transition probabilities: ${ }^{5}$

\footnotetext{
${ }^{5}$ For further details, see Pelagatti (2001, 2002, 2003). As suggested by Kim and Nelson (1998) and Pelagatti (2002, 2003), a probit specification is employed to characterize the duration dependence in the business cycle.
} 


$$
P_{t}(d)=\left[\begin{array}{ll}
p_{0 \mid 0}(d) & p_{0 \mid 1}(d) \\
p_{1 \mid 0}(d) & p_{1 \mid 1}(d)
\end{array}\right]=\left[\begin{array}{cc}
\mathbf{\Phi}\left(-\beta_{3}-\beta_{4} d\right) & \mathbf{\Phi}\left(-\beta_{1}-\beta_{2} d\right) \\
1-\boldsymbol{\Phi}\left(-\beta_{3}-\beta_{4} d\right) & 1-\boldsymbol{\Phi}\left(-\beta_{1}-\beta_{2} d\right)
\end{array}\right]
$$

where $\Phi(\cdot)$ is the standard normal cumulative distribution function and $p_{i \mid j}(d)=\operatorname{Pr}\left(S_{t}=\right.$ $\left.i \mid S_{t-1}=j ; D_{t-1}=d\right)$ represents the probability of the economy being in state $i$ in period $t$ given that in the previous period it was in state $j$ with duration $d$. Moreover, $d=1, \ldots, \tau$, and it is assumed that the maximum duration is equal to $\tau$, with $0<\tau<T$, where $T$ is the length of the time series being modelled. This maximum value $(\tau)$ for the duration variable $D_{t}$ must be fixed, so that the Markov chain $\left(S_{t} ; D_{t}\right)$ is defined in a finite state space. All this means that the transition probability matrix is completely defined by four parameters of $\boldsymbol{\beta}=\left(\beta_{1}, \beta_{2}, \beta_{3}, \beta_{4}\right)$. If $\beta_{2}=\beta_{4}=0$, then we have fixed transition probabilities or no business cycle duration dependence.

To obtain parameter estimates from the duration dependent Markov-switching model, we may employ either a quasi-maximum likelihood estimator or a Gibbs sampler approach. In this study, we adopt the latter approach. ${ }^{6}$ To perform all the required econometric procedures, we use the DDMSVAR code for Ox developed by Pelagatti (2003). ${ }^{7}$

\section{Empirical Results}

To test for the presence of duration dependence in the US business cycle, Pelagatti (2002, 2003) applies the DDMSVAR model to the monthly growth rate of industrial production, nonfarm-employment, manufacturing and trade sales, and personal income over the period January 1960 to August 2001. ${ }^{8}$ These are considered the most important time series on which the NBER relies to date the US business cycle. The ECRI employs a set of similar

\footnotetext{
${ }^{6}$ For a detailed explanation on how the Gibbs sampler is implemented to the DDMSVAR model, see Pelagatti (2002, 2003). To estimate the uknown MSVAR parameters, Durland and McCurdy (1994) use a quasi-maximum likehood estimator, while Kim and Nelson (1998) and Pelagatti (2002, 2003) employ the Bayesian Markov Chain Monte Carlo (MCMC) method. An interesting analysis of several specifications and estimations of the MS model can be found in Kim and Nelson (1999).

${ }^{7}$ We would like to thank Matteo Pelagatti for making his DDMSVAR code for Ox publicly available in his website: http://www.statistica.unimib.it/utenti/p_matteo/

${ }^{8}$ See also the extension to the Turkish economy provided by Ozun and Turk (2009).
} 
monthly economic indicators - industrial production, employment, real personal income, sales, and monthly estimates of real GDP - to identify the business cycle turning points in some economies.

Given the importance of these variables, we decided to consider them to identify the Portuguese business cycle. However, monthly data are not available for most of those series. Only the industrial production has been recorded on a monthly basis for a reasonable period of time (since 1955). ${ }^{9}$ As a way of overcoming this problem, we decided to combine the information contained in the industrial production index $(I P)$ with a composite leading indicator $(C L I)$ computed by the OECD, for which data is available since 1977 . The $C L I$ can be considered as a proxy for the information contained in the other series since it comprises data on related variables. ${ }^{10}$ Moreover, leading indicators are designed to signal fluctuations in economic activity and, therefore, they are considered important in explaining the transition probabilities between expansions and contractions and able to improve the quality and predictive power of the underlying model. ${ }^{11}$ For these reasons, the $C L I$ will be used, together with the $I P$, in the estimation of the DDMSVAR model for the Portuguese economy. ${ }^{12}$ In particular, the empirical model will be applied to 100 times the difference of the logarithm of these two variables for the period January 1978 to October 2010. This means that annual growth rate of those variables (on year-on-year growth rates, i.e. compared to the same month of the previous year) are used in this analysis. Descriptive statistics for these variables are provided in Table $1 .^{13}$

\section{$<$ Insert Table 1 around here $>$}

The estimates of the DDMSVAR model for the growth rates of IP $(d l I P)$ and $C L I$

\footnotetext{
${ }^{9}$ Monthly data are also available for sales, but this series starts only in the mid-1990s.

${ }^{10}$ For further details on the components of the $C L I$ and on the methodology to compute it, contact the OECD directly at http://www.oecd.org/std/cli. The source for the data used in this analysis is OECD, Main Economic Indicators, February 2011.

${ }^{11}$ See, among others, Kim and Nelson (1998), Layton and Smith (2007) and Castro (2010).

${ }^{12}$ An alternative would be to rely on the fluctuation of GNP or GDP series - like Pelagatti (2001) and Chen and Shen (2006) - but the available quarterly data for these series for Portugal start only in 1996. Despite the small sample period, some attempts were made, but the model did not work well: expansions and contractions were not clearly identifiable. The same happened when $I P$ was the only series used in the model.

${ }^{13}$ There, we also find information for the annual growth rate of civilian employment. Monthly data for employment was obtained by linear interpolation of the available quarterly data for the period 1983-2010.
} 
$(d l C L I)$ are presented in Table $2 .{ }^{14}$ The scalar for the maximum duration $(\tau)$ is assumed to be 60 months (or 5 years), which shall be enough to identify the presence of duration dependence in the business cycle phases. The number of lags $(p)$ was set as equal to 0. Some lags were tried, but the model did not work well, making the identification of expansions and contractions unclear. ${ }^{15}$ The priors to the vectors of parameters $\boldsymbol{\mu}$ and $\boldsymbol{\beta}$ were chosen to focus the sampling in an economically reasonable set of values. ${ }^{16}$ The Gibbs sampler was run for 11000 iterations, of which the first 1000 were discarded, and the remaining 10000 sample points were used to estimate the densities and the posteriors presented in Table $2 .{ }^{17}$

$<$ Insert Table 2 around here $>$

Besides the mean and standard deviation of the posteriors, the median (50\%) and the $95 \%$-credibility intervals of the posterior distributions - based on the $2.5^{\text {th }}$ and the $97.5^{\text {th }}$ percentiles of the 10000 simulated draws - are also presented. Considering the mean of the posterior distributions for the estimates of $I P$ and $C L I$ growth rates $(\boldsymbol{\mu})$, we obtain mean growth rates of about $-2.5 \%$ and $-2.9 \%$, respectively, during a contraction $\left(\mu_{0}\right)$, and expansion mean growth rates $\left(\mu_{0}+\mu_{1}\right)$ of about $4.2 \%$ and $4.4 \%$, respectively. According to the $95 \%$-credibility intervals, all the coefficients of the vector $\boldsymbol{\mu}$ are statistically significant.

The estimates of $\boldsymbol{\beta}$ are displayed next. The constants $\left(\beta_{1}\right.$ and $\left.\beta_{3}\right)$ present the expected signs and are clearly different from zero. However, the coefficients of most interest are the duration dependence coefficients $\beta_{2}$ and $\beta_{4}$. The concentration of the posterior of the parameter $\beta_{2}$ around zero seems to indicate that the probability of falling into a contraction is independent on how long the economy has been in expansion. Hence, an expansion regime tends to display strong persistence, which means that the likelihood of the economy leaving

\footnotetext{
${ }^{14}$ The OECD call to $d l C L I$ the year-on-year growth rate of the $C L I$ and considers it as the preferred pointer to identify turning points because it is less volatile and provides earlier and clearer signals for their identification than the $C L I$ itself.

${ }^{15}$ As in Pelagatti (2003, p. 15), we argue that this is probably due to the fact that the DDMS model is a stationary process, which can then be approximated with an autoregressive model. Hence, the duration dependent switching part and the VAR part try to explain almost the same features of the series and the model is not too well identified.

${ }^{16}$ Other priors were tried, including 0 for all variables, but results were quite similar. Those results are available upon request. As in Pelagatti (2001, 2002), no specific prior was defined for matrix $\boldsymbol{\Sigma}$.

${ }^{17}$ The Gibbs sampler always reached convergence to its stationary distribution. To save space their graphs are not presented here, but they are available upon request. The same applies to the kernel density estimates/distributions of $\boldsymbol{\mu}$ and $\boldsymbol{\beta}$.
} 
this state is low and relatively constant over time and, therefore, not affected by its duration. In other words, this means that expansions are not duration dependent. The posterior of $\beta_{4}$ is away from zero, but only marginally (statistically) significant since its $95 \%$-confidence interval still includes the value $0 .{ }^{18}$ However, it remains some evidence of positive duration dependence of the transition probability of moving into an expansion after a period of contraction $\left(\operatorname{Pr}\left(S_{t}=1 \mid S_{t-1}=0, D_{t-1}=d\right)\right)$, which can be confirmed in Figure 1 . The probability of a contraction ending indeed increases over time, but at a slow pace. Hence, there is some (weak) evidence of positive duration dependence for contractions, ${ }^{19}$ but no duration dependence is found for expansions. ${ }^{20}$

\section{$<$ Insert Figure 1 around here $>$}

Next we intend to identify the periods of expansion and contraction estimated by the model. The estimated probabilities of the Portuguese economy being in expansion over the period 1978-2010 are presented in Figure 2. ${ }^{21}$ The model proved to have a reasonable capability of discerning expansions and contractions, as the probabilities of expansions, in general, tend to assume high and low values. These probabilities of expansion can be used to identify the turning points (peaks and troughs) in the Portuguese economy over the period 1978-2010. Making use of Hamilton's (1989) 0.5-rule to determine the state of the economy, we end up with the business cycle chronology presented in Table 3.

$<$ Insert Figure 2 around here $>$

$<$ Insert Table 3 around here $>$

Four periods of contraction are clearly identified by the model: October 1983 to June 1984; March 1991 to November 1993; May 2001 to February 2006; and May 2007 to November 2009. ${ }^{22}$ These contractions coincide quite remarkably with world crises. The contraction that

\footnotetext{
${ }^{18}$ For a $90 \%$-confidence interval that is no longer the case.

${ }^{19}$ However, we will see below that the additional information contained in the (annual growth rate of the) employment variable will be helpful in unveiling the presence of positive duration dependence in contractions.

${ }^{20}$ Note that, in Figure 1, the mean of the transition probability of moving into a contraction after a period of expansion, i.e. $\operatorname{Pr}\left(S_{t}=0 \mid S_{t-1}=1, D_{t-1}=d\right)$, is flat.

${ }^{21}$ For details on how these probabilities are computed, please see Pelagatti's (2003) code.

${ }^{22}$ Note that our chronology also identifies reasonably well the two periods of low growth pointed out by Dias (2003) for the first half of the 1980s and 1990s.
} 
started in October 1983 and ended in June 1984, follows the international crisis caused by a monetary policy tightening in the US to control inflation, which boosted a debt crisis in some less developed countries. In this period, Portugal was also economically affected by the introduction of some austerity measures imposed by the IMF in exchange for financial help to avoid bankruptcy. The contraction in the beginning of the 1990s is the repercussion of the stock crash in the late 1980s in the US that lead to a recession in many industrialized countries. $^{23}$ The early 2000s contraction is in line with the crisis caused by the burst of the Dot Com bubble and the September 2001 attacks. Finally, the contraction May 2007November 2009 matches the financial crisis that has affected the world in the late 2000s. Considering this last two contraction periods, we may argue that the 2000s can be seen as a "lost decade" for Portugal in terms of economic expansion.

Although this specification is able to produce a clearer chronology for Portuguese business cycle, the presence of positive duration dependence in contractions - however weak - seems to fade away. Given this evidence, we could be tempted to conclude that either the likelihood of a contraction ending is not indeed affected by its duration or annual growth rates are simply hiding out some useful information to detect its presence. To explore a little more this issue, we decided to keep the annual growth rates of $I P$ and $C L I$ in the model and tried to add additional information/variables to the model. The problem is - as already noticed - that monthly data for other useful variables (employment, sales, income,...) are not available for a reasonable period of time or they are not available at all. However, we found that quarterly data for an index of civilian employment (Emp) is available since 1983. As the changes in this variable are more or less smooth over time, we consider that a linear interpolation of quarterly data, to generate monthly data, would produce a series that might be very close to the actual monthly time series. Following this procedure, we generated monthly data for Emp and then computed the respective annual growth rates compared to the same month of the previous year $(d l E m p) .{ }^{24}$ This variable was then added to the model. The results of the DDMSVAR model with $d l I P, d l C L I$ and $d l E m p$ for the shorter period of June 1984 to October 2010 are presented in Table 4 .

\footnotetext{
${ }^{23}$ The Golf War, the German reunification and the problems with the European Exchange Rate Mechanisms also contributed, in some degree, to the international recession.

${ }^{24}$ See Table 1 for descriptive statistics.
} 
Once again, the choice of the priors to the vectors of parameters $\boldsymbol{\mu}$ and $\boldsymbol{\beta}$ was based on a set of sensible values. ${ }^{25}$ The results present annual growth rates of about $-2.1 \%(3.8 \%)$ for $I P,-3.9 \%(3.8 \%)$ for $C L I$, and $-1.1 \%$ (1.5\%) for Emp during contractions (expansions), and all the coefficients are statistically significant according to the $95 \%$-credibility intervals.

The estimates of the duration dependence coefficients $\left(\beta_{2}\right.$ and $\left.\beta_{4}\right)$ present quite interesting results. First, the concentration of the posterior of the parameter $\beta_{2}$ around zero confirms that the probability of falling into a contraction is independent of how long the economy has been in expansion, strengthening the previous conclusion that Portuguese expansions are not duration dependent. Second, the posterior of $\beta_{4}$ now lays significantly away from zero; statistically, it can be considered different from zero since its 95\%-confidence interval does not include the value 0 . Therefore, positive duration dependence is present in Portuguese contractions. This evidence can be confirmed in Figure 3, where it is very clear the increase (over time) in the transition probability of the economy moving into an expansion after a period of contraction $\left(\operatorname{Pr}\left(S_{t}=1 \mid S_{t-1}=0, D_{t-1}=d\right)\right)$.

$<$ Insert Figure 3 around here $>$

The additional information contained in the employment variable has proved to be relevant to detect the presence of positive duration dependence in contractions. ${ }^{26}$ We should notice that these results must be analysed with some care since the gains in terms of additional economic information were obtained at the cost of some missing years of observations and linear interpolation from quarterly data for civilian employment.

Finally, it would be interesting to identify the business cycle chronology that results from this new specification. The periods of expansion and contraction for the period 1984-2010 are presented in Figure 4 and the corresponding chronology is reported in Table 5.

\footnotetext{
${ }^{25}$ Other priors were tried but results were quite similar. Those results are available upon request. This specification also considers $\tau=60$ and $p=0$, and the Gibbs sampler was run for the same number of iteractions as the other estimations presented above.

${ }^{26}$ Several combinations of annual and monthly growth rates of $I P, C L I$ and Emp were also tried but results and conclusions regarding the presence of duration dependence and the respective business cycle chronology remained practically the same. In particular, when only monthly growth rates of those three variables are used, results are quite similar to the ones presented, in first place, in this section. The problem is that the time period is shorter, which means that the contraction in 1983 is missed. All those estimations and results are not reported here due to space limitations, but they are available upon request.
} 
$<$ Insert Figure 4 around here $>$

$<$ Insert Table 5 around here $>$

The general pattern of the periods of contraction and expansion in the Portuguese economic activity is very close to the one identified above in Figure 2 and Table 3. There are, however, some differences that should be considered. First, as the time period is now shorter (it starts in June 1984), it is impossible to identify the contraction that took place in 1983. But Figure 4 is suggestive of its presence since it indicates probabilities lower than 1 in 1984 .

Second, the model now indicates that the contraction in the early 1990s seems to have started in December 1991 and not in March 1991 - as estimated by the model without the annual growth rate of Emp - but the ending date is the same (November 1993). With little differences, both models are successful in identifying this contraction.

Third, the model considers the period of July 1995 to July 1996 as a period of contraction, but the probability of expansion is not close to 0 as in the other cases of contraction; in fact, it is very close to the 0.5 -threshold, which makes this a less relevant and "weak" contraction. Moreover, it does not find support neither in Figure 2 nor in Table 3.

Fourth, both models identify May 2001 as the starting month for the first contraction in the 2000s, but the model with Emp seems to indicate that the recovery has started sooner. Nevertheless, this recovery is not very strong, since the probability of expansion only jumps to values close to 1 in the beginning of 2006. Not surprisingly, this matches quite closely the date reported by the model without Emp for the end of this contraction (February 2006). The differences identified in the estimates provided by both models might be due to the fact that 2004 and 2005 are characterised by a low economic growth in comparison with the average standards. This observation can be confirmed in Figure 5, where the series of real GDP growth over the period 1971-2010 is presented together with the contraction periods identified by both models: above the $x x$-axis we have the recessions identified by the model without Emp (in light-grey); below the $x x$-axis, are presented the recession periods identified by the model with Emp (in dark-grey).

$<$ Insert Figure 5 around here $>$ 
The annual growth rate of GDP is low in 2004 and even falls in 2005. Hence, the model without Emp identifies it as a state of contraction (given that the average growth rate is in the low state), while the model with Emp considers it a period of expansion, however, not very strong given that the probability of expansion is far from 1 until the beginning of 2006. Given all this evidence, we prefer consider it as a period of contraction (or not full recovery). In general, the contraction periods estimated by the DDMS models for the Portuguese economy match very closely the years of low or negative growth of real GDP: 1983-1984; 1992-1993; 2002-2003; 2005; and 2008-2009.

Finally, we should stress that the model with Emp is quite successful in identifying the recent contraction in the Portuguese economic activity caused by the recent financial crisis (July 2007-October 2009). In particular, those dates are very close to the ones reported by the model without Emp (see Table 3).

Thus, the DDMS model with the annual growth rates of $I P, C L I$ and Emp (estimated over the period June 1983-October 2010) together with the model without Emp (estimated over the period January 1978-October 2010) seem to provide a reasonable picture of the Portuguese business cycle chronology over the last 33 years and also some support for the presence of positive duration dependence in contractions.

\section{Conclusions}

The identification of the business cycle chronology for the US economy has been undertaken by the NBER for a long period of time. More recently, the CEPR and the ECRI have extended such task to the Euro Area and to other market oriented economies, respectively. However, the identification of the Portuguese business cycle chronology has been out of their scope. Even the few existing studies on the Portuguese business cycle have not clearly focused in identifying its chronology. Hence, using a recent dataset and a suitable econometric procedure, we identified the periods of expansion and contraction in the Portuguese economy over the last decades.

Another task of this study was to analyse the presence of duration dependence in the 
phases of the Portuguese business cycle. The issue of whether the likelihood of an expansion or contraction ending is dependent on its age has been studied in several papers for a reasonable group of countries, with special attention given to the US. Duration analysis and Markov-switching models have been the mainly used approaches in those studies. Most of them have been successful in finding evidence of positive duration dependence for expansions and/or contractions. Unfortunately, no study has analysed yet this issue for the Portuguese economy. As far as we are concerned, our study represents the first attempt to analyse the presence of duration dependence in the phases of the Portuguese business cycle.

With the aims of identifying the business cycle chronology for the Portuguese economy and the presence of duration dependence in its phases, we employed a model able to deal with both tasks at the same time: the DDMSVAR model developed by Pelagatti $(2001,2002)$. In its specification, we combined monthly data of the industrial production index with monthly information contained in the OECD composite leading indicator, which aggregates some variables that are expected to influence the business cycle. This model proved to have a good capability of discerning periods of contraction and expansion and in finding the presence of duration dependence. In particular, it was able to identify a reasonable chronology for the Portuguese business cycle using year-on-year growth rates of those variables. Four important periods of contraction were identified by this model for the period 1978-2010: October 1983June 1984; March 1991-November 1993; May 2001-February 2006; and May 2007-November 2009. However, we should notice that the ending date for the first contraction in the 2000s revealed to be different when some additional information from civilian employment was added to the model. In that case, the ending date turns out to be September 2003. This result should be analysed with a grain of salt because that variable presented some drawbacks: first, monthly series for that variable were not available, so they had to be generated by linear interpolation from quarterly data; second, its growth rate was only available from June 1984 onwards, which reduced the time-span of the analysis.

Despite these limitations, the two contractions registered in the 2000s and the low economic growth that has caracterised the short periods of expansion during this decade show that Portugal has lost some momentum in achieving higher levels of economic convergence 
to the European Union average during that decade. This represents a big concern for the next years since strong economic expansion is needed to serve private and public debt that was accumulated during the last decade.

Finally, the model was also able to detect the presence of positive duration dependence for contractions, while the likelihood of an expansion ending is not affected by its duration. Therefore, we can conclude that the likelihood of a contraction ending increases over time, but for expansions it remains constant. In sum, these results for the Portuguese business cycles are similar to the ones obtained in several studies for the US: contractions are duration dependent, while expansions are not.

\section{Acknowledgements}

The author wishes to thank the participants at the 5th Annual Meeting of the Portugese Economic Journal, University of Aveiro, 8-9 July 2011, for their most interesting comments and suggestions. The author also thanks the financial support provided by the Portuguese Foundation for Science and Technology under research grant PEst-C/EGE/UI3182/2011 (partially funded by COMPTE, QREN and FEDER).

\section{References}

[1] Afonso A, Claeys P, Sousa R (2011) Fiscal regime shifts in Portugal. Portuguese Economic Journal 10:83-108.

[2] Agnello L, Sousa R. (2011). Can fiscal stimulus boost economic recovery? Revue Économique, 62(6):1045-1066.

[3] Agnello L, Sousa, R (2013). Fiscal policy and asset prices. Bulletin of Economic Research, 65(2):154-177.

[4] Agnello L, Schuknecht, L (2011). Booms and busts in housing markets: Determinants and implications. Journal of Housing Economics, 20(3):171-190. 
[5] Artis M, Krolzig H-M, Toro J (2004) The European business cycle. Oxford Economic Papers 56:1-44.

[6] Bry G, Boschan C (1971) Cyclical Analysis of Time Series: Selected Procedures and Computer Program. National Bureau of Economic Research, New York.

[7] Burns A, Mitchell W (1946) Measuring Business Cycles. NBER Studies in Business Cycles, No. 2. National Bureau of Economic Research, New York.

[8] Castro V (2010) The duration of economic expansions and recessions: More than duration dependence. Journal of Macroeconomics 32:347-365.

[9] Cavalcanti T (2007) Business cycle and level accounting: the case of Portugal. Portuguese Economic Journal 6:47-64.

[10] Chen S, Shen C (2006) Is there a duration dependence in Taiwan's business cycles. International Economic Journal 20:109-127.

[11] Correia I, Neves J, Rebelo S (1992) Business Cycles in Portugal: Theory and Evidence. In J. F. Amaral, D. Lucena and A. S. Mello Eds. The Portuguese Economy towards 1992, pp. 1-64. Boston: Kluwer Academic Publishers.

[12] Davig T (2007) Change-points in US business cycle durations. Studies in Nonlinear Dynamics and Econometrics 11(2), Article 6.

[13] Dias F (2003) Nonlinearities over the Business Cycle: an Application of the Smooth Transition Autoregressive Model to Characterize GDP Dynamics for the Euro-Area and Portugal, Working Paper WP 9-03, Bank of Portugal.

[14] Dias M (1997) Analise da Evolução Ciclica da Economia Portuguesa no Periodo de 1953 a 1993. Bank of Portugal, Economic Bulletin, September 1997, pp. 77-83.

[15] Diebold F, Rudebusch G, Sichel D (1990) International evidence on business cycle duration dependence. Institute for Empirical Macroeconomics, DP 31. 
[16] Diebold F, Rudebusch G, Sichel D (1993) Further evidence on business cycle duration dependence. In: J. H. Stock and M. W. Watson Eds. Business Cycles, Indicators, and Forecasting, pp. 87-116. Chicago: University of Chicago Press.

[17] Durland M, McCurdy T (1994). Duration-dependent transitions in a Markov model of US GNP growth. Journal of Business and Economic Statistics 12:279-288.

[18] Fisher I (1925) Our unstable dollar and the so-called business cycle. Journal of American Statistical Association 20:179-202.

[19] Hamilton J (1989) A new approach to the economic analysis of nonstationary time series and the business cycle. Econometrica 57:357-384.

[20] Harding D, Pagan A (2002) Dissecting the cycle: A methodological investigation. Journal of Monetary Economics 49:365-381.

[21] Kim C, Nelson C (1998) Business cycle turning points, a new coincident index, and tests of duration dependence based on a dynamic factor model with regime switching. Review of Economics and Statistics 80:188-201.

[22] Kim C, Nelson C (1999) State Space Models with Regime Switching: Classical and GIBBS-Sampling Approaches with Applications. The MIT Press, Cambridge.

[23] Krolzig H-M (1997) Markov-Switching Vector Autoregressions. Modelling, Statistical Inference and Application to Business Cycle Analysis. Springer, Berlin.

[24] Krolzig H-M (2001) Markov-switching procedures for dating the Euro-Zone business cycle. Quarterly Journal of Economic Research 70:339-351.

[25] Krolzig H-M, Toro J (2005) Classical and modern business cycle measurement: The European case. Spanish Economic Review 7:1-21.

[26] Layton A, Smith D (2007). Business cycle dynamics with duration dependence and leading indicators. Journal of Macroeconomics 29:855-875.

[27] Mallick S, Sousa R (2013) The real effects of financial stress in the Euro zone. International Review of Financial analysis 30:1-17. 
[28] Neves J (1994) The Portuguese Economy: a Picture in Figures. Lisbon: Portuguese Catholic University.

[29] Neves P and Belo F (2002) Evolução Ciclica da Economia Portuguesa no Periodo de 1910 a 1958: uma breve analise. Bank of Portugal, Economic Bulletin, March 2002, pp. $57-69$.

[30] Ozun A, Turk M (2009) A duration-dependent regime switching model for an open emerging economy. Romanian Journal of Economic Forecasting 4:66-81.

[31] Pelagatti M (2001) Gibbs sampling for a duration dependent Markov-switching model with application to the US business cycle. Working Paper, Quaderno di Dipartimento QD2001/2 (March), Dipartimento di Statistica, Universita degli Studi di Milano Bicocca.

[32] Pelagatti M (2002) Duration-dependent Markov-switching VAR models with applications to the business cycle analysis. Proceedings of the XLI Scientific Meeting of the Italian Statistics Society.

[33] Pelagatti M (2003) DDMSVAR for Ox: A software for time-series modeling with duration-dependent Markov-switching autoregressions. 1st OxMetrics User Conference, London, September 1-2, 2003.

[34] Sichel D (1991) Business cycle duration dependence: A parametric approach. Review of Economics and Statistics 73:254-260.

[35] Schirwitz B (2009) A comprehensive German business cycle chronology. Empirical Economics 37:287-301.

[36] Sousa R (2010). Housing wealth, financial wealth, money demand and policy rule: evidence from the euro area. The North American Journal of Economics and Finance, 21(1):88-105.

[37] Zuehlke T (2003) Business cycle duration dependence reconsidered. Journal of Business and Economic Statistics 21:564-569. 


\section{List of Tables}

Table 1 - Descriptive Statistics

\begin{tabular}{lcccccr}
\hline \hline Variable & period & obs. & mean & st.dev. & min. & max. \\
$d l I P$ & $1978 M 1-2010 M 10$ & 394 & 2.054 & 5.120 & -16.88 & 14.61 \\
$d l C L I$ & $1978 M 1-2010 M 10$ & 394 & 2.104 & 4.783 & -15.56 & 11.43 \\
$d l E m p$ & $1984 M 6-2010 M 10$ & 317 & 0.727 & 2.616 & -7.82 & 7.32 \\
\hline \hline
\end{tabular}

Notes: For further details on the components of the $C L I$ and on the methodology to compute it, contact the OECD directly at http://www.oecd.org/std/cli.

Source: OECD, Main Economic Indicators, December 2010.

Table 2 - Estimates of the DDMSVAR model

\begin{tabular}{l|rc|rrrrr}
\hline \hline & \multicolumn{3}{|c}{ Prior } & \multicolumn{5}{c}{ Posterior } \\
Parameter & mean & var. & \multicolumn{1}{c}{ mean } & st.dev. & $2.5 \%$ & $50.0 \%$ & $97.5 \%$ \\
\hline$\mu_{0} d l I P$ & -2.000 & 4.000 & -2.4900 & 0.3740 & -3.2263 & -2.4887 & -1.7522 \\
$\mu_{0} d l C L I$ & -2.000 & 4.000 & -2.8757 & 0.3189 & -3.5060 & -2.8720 & -2.2633 \\
\hline$\mu_{1} d l I P$ & 5.000 & 4.000 & 6.6779 & 0.4368 & 5.8138 & 6.6793 & 7.5343 \\
$\mu_{1} d l C L I$ & 5.000 & 4.000 & 7.3153 & 0.3587 & 6.6018 & 7.3186 & 8.0285 \\
\hline$\beta_{1}$ & 1.000 & 5.000 & 2.5681 & 0.5167 & 1.6409 & 2.5429 & 3.6787 \\
$\beta_{2}$ & 0.000 & 5.000 & -0.0085 & 0.0104 & -0.0296 & -0.0082 & 0.0117 \\
$\beta_{3}$ & -1.000 & 5.000 & -2.4945 & 0.5209 & -3.6485 & -2.4576 & -1.5876 \\
$\beta_{4}$ & 0.000 & 5.000 & 0.0260 & 0.0225 & -0.0076 & 0.0225 & 0.0886 \\
\hline \hline
\end{tabular}

Notes: Time-period: January 1978 - October 2010. 
Table 3 - Business cycle chronologies

\begin{tabular}{|c|c|c|c|c|c|}
\hline \multicolumn{2}{|c|}{ Business cycle reference dates } & \multicolumn{4}{|c|}{ Duration (in months) } \\
\hline \multirow[t]{2}{*}{ Peak } & \multirow[t]{2}{*}{ Trough } & \multirow{2}{*}{$\begin{array}{l}\text { Contraction } \\
\text { Peak-Trough }\end{array}$} & \multirow{2}{*}{$\begin{array}{l}\text { Expansion } \\
\text { Trough-Peak }\end{array}$} & \multicolumn{2}{|c|}{ Cycle } \\
\hline & & & & Trough-Trough & Peak-Peak \\
\hline- & December $1977^{+}$ & - & - & - & - \\
\hline October 1983 & June 1984 & 8 & $70^{+}$ & $78^{+}$ & - \\
\hline March 1991 & November 1993 & 32 & 81 & 113 & 89 \\
\hline May 2001 & February 2006 & 57 & 90 & 147 & 122 \\
\hline May 2007 & November 2009 & 30 & 15 & 45 & 72 \\
\hline \multirow[t]{2}{*}{ October $2010^{+}$} & - & - & $11^{+}$ & - & $41^{+}$ \\
\hline & verage ( 4 cycles) & 32 & 62 & 102 & 94 \\
\hline
\end{tabular}

Notes: + indicates that the duration can be higher because the date of the respective trough or peak has been censored since they are out of the sample (January 1978-October 2010) and they are not known. December 1977 and October 2010 are assumed to be the reference (censored) dates, but the real trough/peak might be further away in the past or in the future, respectively. The censored durations are not considered in the computation of the averages.

Table 4 - Estimates of the DDMSVAR model with $d l E m p$

\begin{tabular}{l|rc|rrrrr}
\hline \hline & \multicolumn{2}{|c}{ Prior } & \multicolumn{5}{c}{ Posterior } \\
Parameter & mean & var. & mean & st.dev. & $2.5 \%$ & $50.0 \%$ & $97.5 \%$ \\
\hline$\mu_{0} d l I P$ & -2.000 & 4.000 & -2.0846 & 0.9541 & -3.8030 & -1.9082 & -0.5439 \\
$\mu_{0} d l C L I$ & -2.000 & 4.000 & -3.9111 & 0.6851 & -5.3355 & -3.8666 & -2.7388 \\
$\mu_{0} d l E m p$ & -2.000 & 4.000 & -1.0954 & 0.2873 & -1.6921 & -1.0818 & -0.5664 \\
\hline$\mu_{1} d l I P$ & 5.000 & 4.000 & 4.8975 & 1.2662 & 2.9557 & 4.5708 & 7.1275 \\
$\mu_{1} d l C L I$ & 5.000 & 4.000 & 7.7015 & 0.5425 & 6.7127 & 7.6876 & 8.7994 \\
$\mu_{1} d l E m p$ & 5.000 & 4.000 & 2.5978 & 0.3047 & 2.0107 & 2.5946 & 3.1882 \\
\hline$\beta_{1}$ & 1.000 & 5.000 & 2.5837 & 0.6553 & 1.5418 & 2.4987 & 4.2629 \\
$\beta_{2}$ & 0.000 & 5.000 & -0.0112 & 0.0139 & -0.0415 & -0.0102 & 0.0130 \\
$\beta_{3}$ & -1.000 & 5.000 & -3.3109 & 1.0260 & -5.8325 & -3.1299 & -1.8330 \\
$\beta_{4}$ & 0.000 & 5.000 & 0.0878 & 0.0563 & 0.0084 & 0.0787 & 0.2242 \\
\hline \hline
\end{tabular}

Notes: Time-period: June 1984 - October 2010.

Table 5 - Business cycle chronologies (with $d l E m p$ )

\begin{tabular}{|c|c|c|c|c|c|}
\hline \multicolumn{2}{|c|}{ Business cycle reference dates } & \multicolumn{4}{|c|}{ Duration (in months) } \\
\hline \multirow[t]{2}{*}{ Peak } & \multirow[t]{2}{*}{ Trough } & \multirow{2}{*}{$\begin{array}{l}\text { Contraction } \\
\text { Peak-Trough }\end{array}$} & \multirow{2}{*}{$\begin{array}{l}\text { Expansion } \\
\text { Trough-Peak }\end{array}$} & \multicolumn{2}{|l|}{ Cycle } \\
\hline & & & & Trough-Trough & Peak-Peak \\
\hline- & May $1984^{+}$ & - & - & - & - \\
\hline December 1991 & November 1993 & 23 & $91^{+}$ & $114^{+}$ & - \\
\hline July 1995 & July 1996 & 12 & 20 & 32 & 43 \\
\hline May 2001 & September 2003 & 28 & 58 & 86 & 70 \\
\hline July 2007 & October 2009 & 46 & 27 & 73 & 55 \\
\hline \multirow[t]{2}{*}{ October $2010^{+}$} & - & - & $12^{+}$ & - & $58^{+}$ \\
\hline & verage (4 cycles) & 27 & 50 & 76 & 56 \\
\hline
\end{tabular}

Notes: + indicates that the duration can be higher because the date of the respective trough or peak has been censored since they are out of the sample (June 1984-October 2010) and they are not known. May 1984 and October 2010 are assumed to be the reference (censored) dates, but the real trough/peak might be further away in the past or in the future, respectively. In this case, looking at Figure 5 and Table 7, May 1984 might be considered the actual trough, hence the computation of the averages will take it into account, but not the censored duration for the conjectured peak in October 2010. 


\section{List of Figures}

Figure 1 - Transition Probabilities

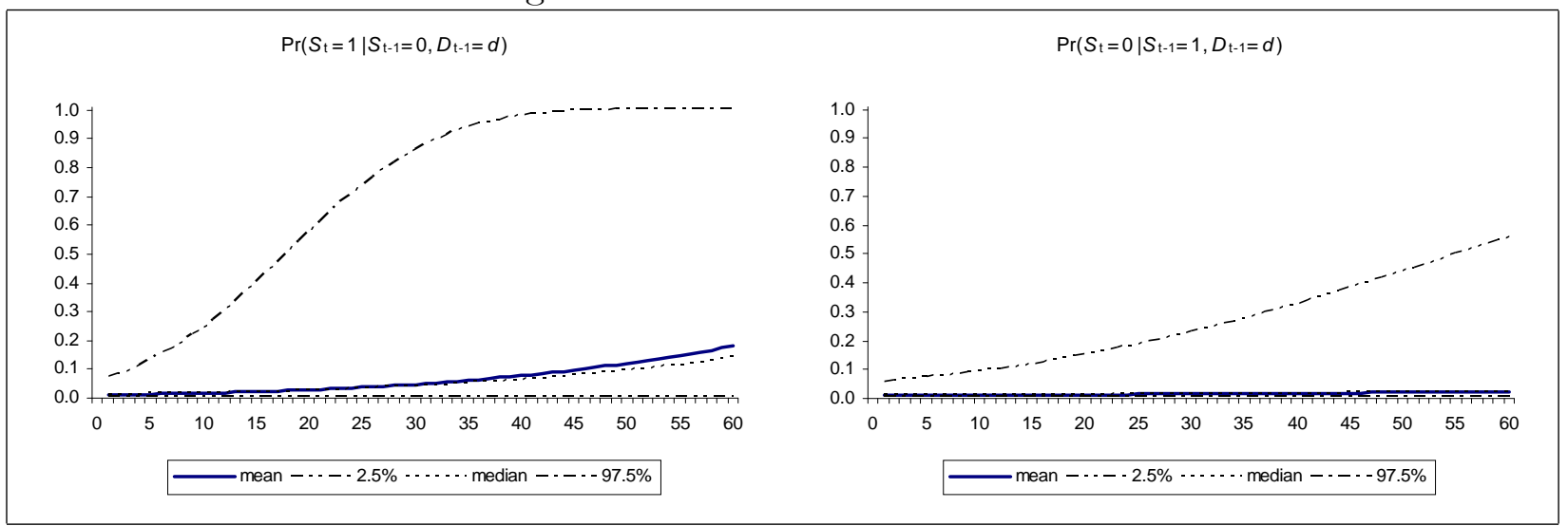

Figure 2 - Probability of expansion

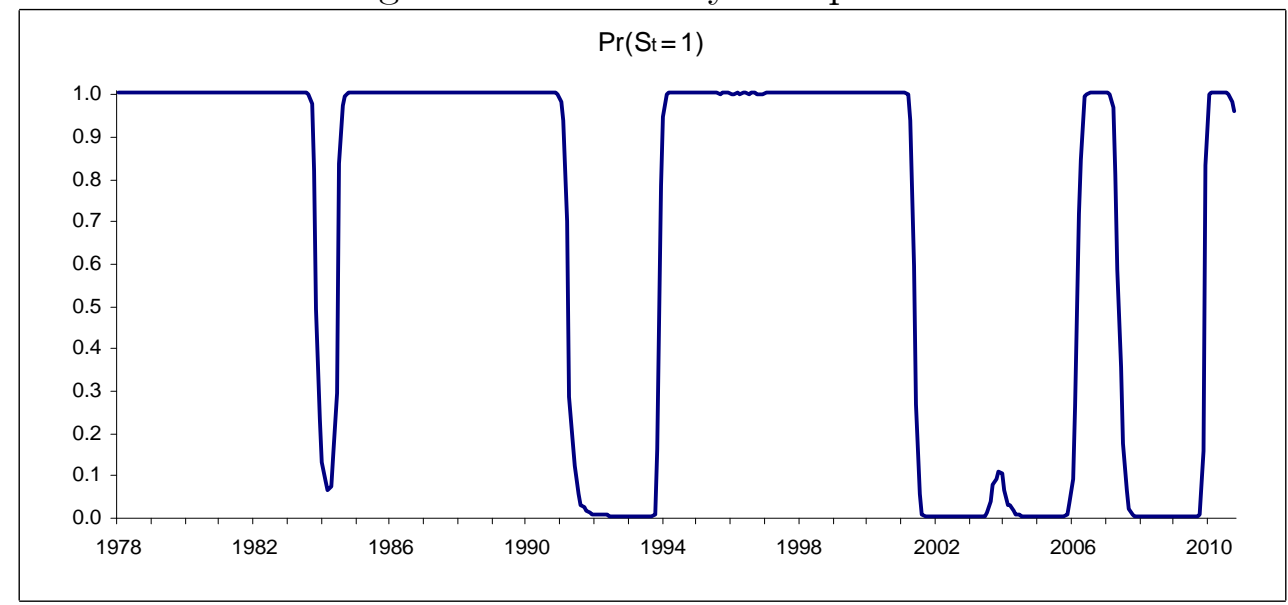


Figure 3 - Transition Probabilities (with $d l E m p$ )

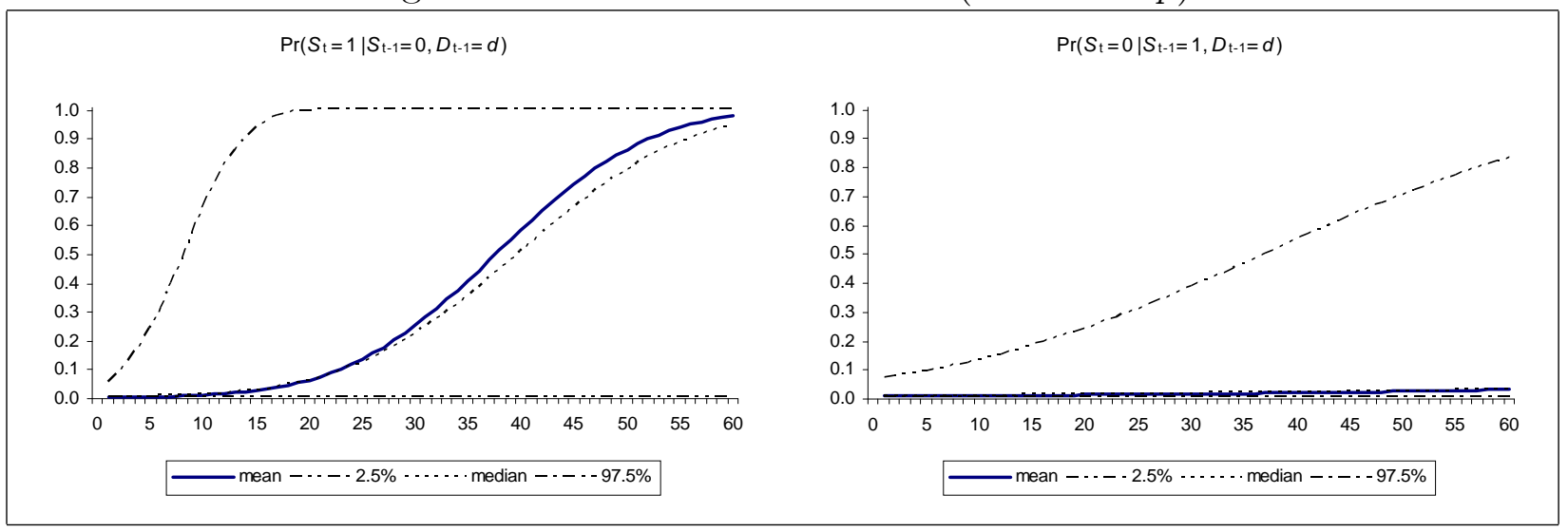

Figure 4 - Probability of expansion (with $d l E m p_{12}$ )

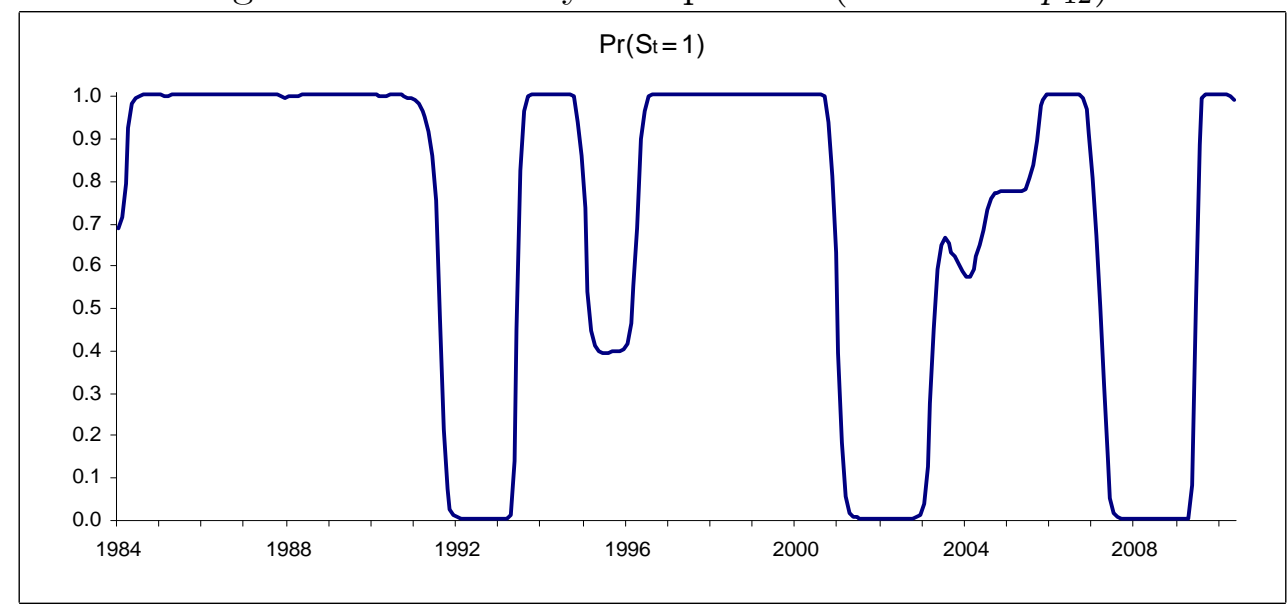

Figure 5 - Annual growth rate of real GDP (\%), 1971-2010

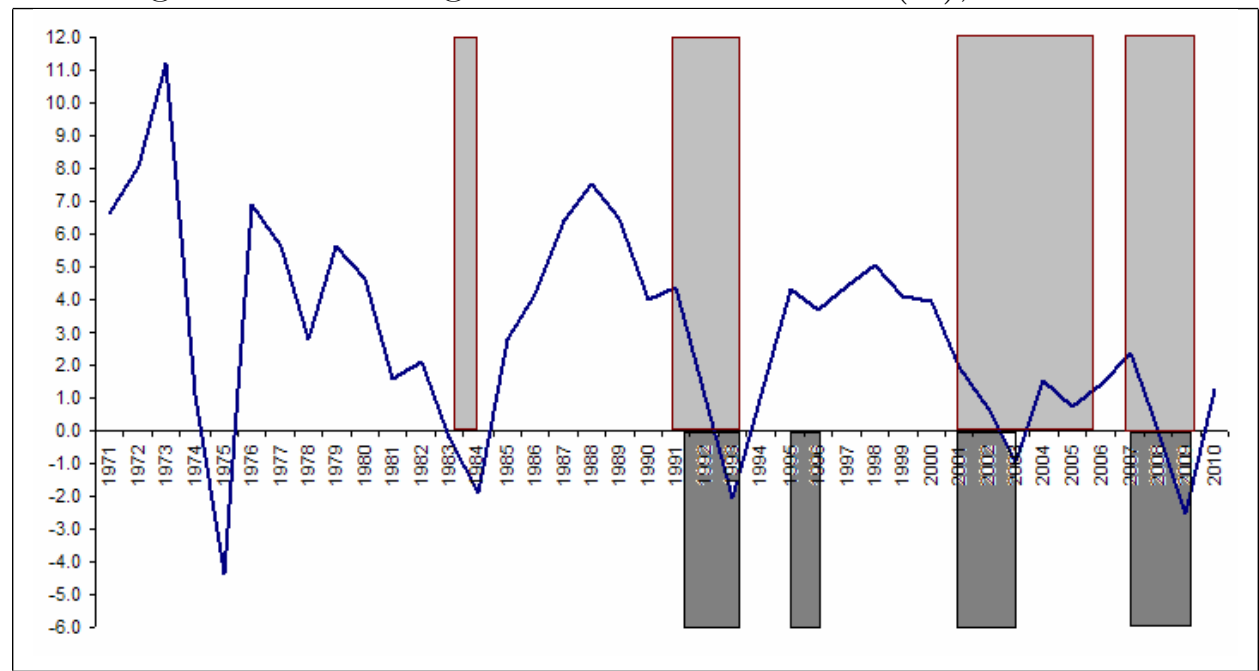

Source: OECD, Main Economic Indicators, December 2010. 